\title{
A Survey on Protocols, Platforms and Simulation Tools for Wireless Sensor Networks
}

\author{
Mohammed Abo-Zahhad*, Osama Amin, Mohammed Farrag and Abdelhay Ali \\ Electrical and Electronics Engineering Department, Faculty of Engineering, \\ Assiut University, Assiut, Egypt \\ Zahhad@yahoo.com
}

\begin{abstract}
Wireless Sensor Networks (WSNs) are becoming very common technology which combine sensing, processing, and wireless multi-hop networking. This paper provides a wide review of the present state about WSNs at the time of its writing. Following a topdown approach, WSNs concept, definition and applications is provided. Furthermore, an overview of WSNs constrains and judgment metrics such as lifetime and latency is given. Then, the communication protocol stack for WSNs is described, and protocols developed for each layer are discussed. Finally, this paper provides review and comparisons of current simulation programs All of these features make the paper valuable for an extensive variety of possible readers, researchers in WSNs, students stating research in WSNs, specialists wanting to offer WSN solutions, and WSN application designers.
\end{abstract}

Keywords: Wireless sensor networks; communication protocol stack; Platforms; Simulator Tools; Ad hoc networks

\section{Introduction}

Wireless Sensor Networks (WSNs), are one of the most important technologies for the current century. Normally, WSNs composed of interconnected sensor nodes that are capable of not only sensing, but also interactive with each other [1-3]. In recent years, WSNs have acquired global attention, mainly with the development of smart sensors which evolved due to spread in Micro-Electro-Mechanical Systems (MEMS) technology [4-6]. The benefits of WSNs allow observing, and control functionality. Probable applications contain environmental monitoring, industrial monitoring and control, alarm and security systems, home automation, and military targeting and exploration [1, 7, 8]. The wiring cost and the extensive implementation time are the main challenges in the implementation of the conventional wired sensor networks. For that reason, the wired sensor networks have been replaced by WSNs. In the WSNs, the deployment is simpler; just drop sensor nodes from the airplane into the target area in place of wiring from the target area to the station. Recently, WSNs have acquired great attention from industry and academia in worldwide. A huge number of study activities has been made to discover and resolve several design issues, and great improvements have been made in the design and development WSNs [9].

The previously described features assure an extensive number of applications for WSNs. For example, doctor can monitor remotely the vital signs for patients. While this allows the doctor to good comprehend the patient's present state, it also is suitable for the patients. Also, sense chemical agents in the surroundings can be made using WSNs. They can assistance detect the type and location of pollutants. Basically, WSNs will supply the user with a good comprehending of the environment $[5,10]$. In general, WSNs applications can be categorized into two groups: monitoring and tracking as shown in Figure 1. Monitoring applications 
comprise indoor/outdoor environmental monitoring, patient monitoring, power monitoring, manufacturing works and process automation, and structural and seismic monitoring. Tracking applications comprise tracking animals, objects, humans, and vehicles $[4,11]$.

Implementation of these and other WSNs applications is limited by the WSNs constraints. The WSNs constraints can be classified into two types; resource and design constraints. Resource constraints comprise a small communication range, limited amount of energy, low processing and limited bandwidth in sensor node. Design constraints are based on the application necessities and depend on the application. The size of the network and the deployment method are mainly depend on the environment $[4,5,12]$. one of the still open research issues in the WSNs technology is how to design WSNs which provide both extended network lifetime and QoS with the constrained power source equipped on the sensor nodes [13]. The root to solve this problem is to increase the energy efficiency of networking so that the largest amount of valuable information can be transferred per unit energy [14]. In other words, we are not merely minimizing the power consumption, but in its place maximizing energy efficiency so that the greatest QoS is delivered within such power constraints.

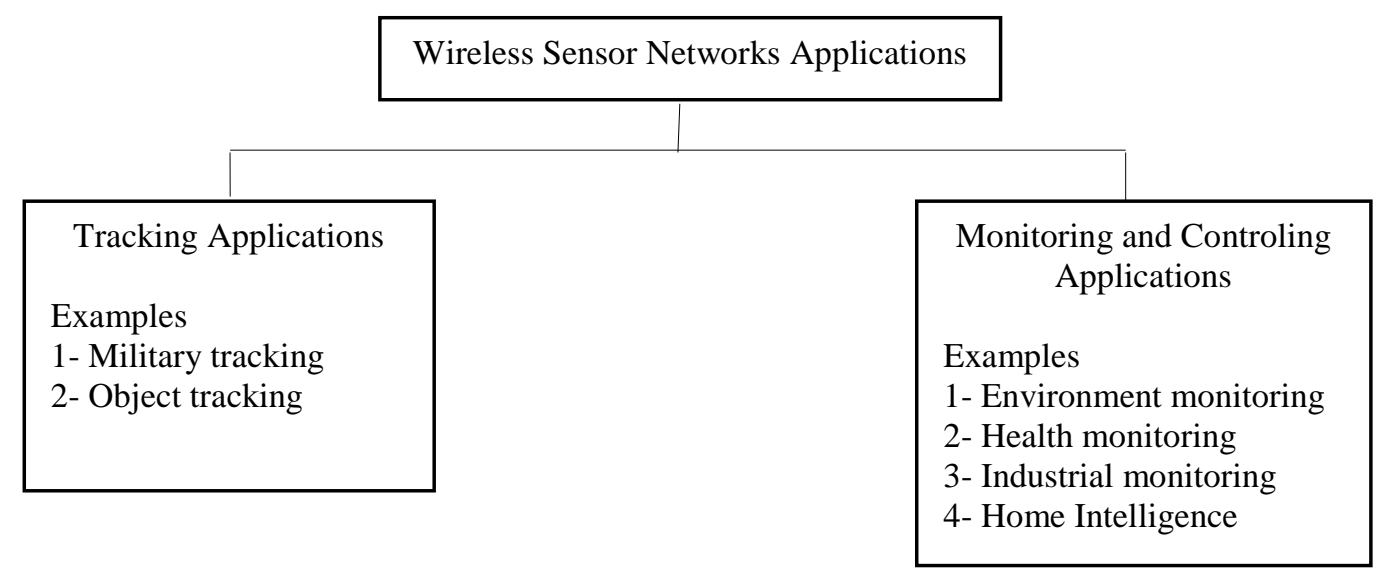

Figure 1. Classification of WSNs Applications

This paper is broadly divided into seven sections; Section 2 discusses judgment metrics on the WSNs. Section 3 relate to the discussion about the hardware structure of sensor nodes. Section 4 focuses on the WSNs platforms. Section 5 discusses the communication protocols in WSNs. Section 6, relating to the issue of simulation programs of WSN. Section 7, concludes this paper.

\section{Judgment Metrics on the WSNs}

A There are several metrics that are used to judge the quality of WSNs. Some of these include;

1) Network Lifetime (LT): which is a significant metric depending on several factors, including lifetime definition, energy consumption model, protocols and network architecture, channel characteristics, and data collection initiation[15].

2) Energy Efficiency (EE): which aims to reduce the amount of energy consumption for a given task (e.g., Energy efficient clustering scheme (EECS) [16]).

3) Energy-Per-Useful-Bit (EPUB): which captures overhead due to physical layer modulation [17]. 
4) Latency: which can be defined as the time required to send a packet through a network from source to the sink [18].

The network lifetime becomes a critical metric used to judge the quality of WSNs, where several techniques have been made to increase the network LT. Some of these include power aware storage, energy-aware MAC protocols, duty-cycling schemes, redundant placement of nodes, data dissemination and routing protocols, and tiered system architectures [19]. As we mentioned above that the network lifetime depends on the definition, so we listed below some common definitions of network lifetime which are used in previous work:

Definition 2.1: Network lifetime can be defined as the time duration from the beginning of the network job to the moment when the first node dies [19].

Definition 2.2: Network lifetime is the maximum time after which the desired network performance cannot be achieved [20].

Definition 2.3: Network lifetime is defined as the time period during which the data rate is preserved above a minimum required data rate [21].

Definition 2.4: Network lifetime is defined as the time duration from start the first transmission in the WSNs to the moment when the number of nodes which have not finished their remaining energy falls below a threshold, which is depended on the type of application [15].

Definition 2.5: Network Lifetime can be defined as the time period which the required Signal-to-Noise Ratio (SNR) at the sink is met with a specific probability [22].

\section{Hardware Structure}

The functionality of a sensing node is generally implemented through four basic units which are; transceiver, processing, sensing and power units as shown in Figure 2. The transceiver unit allows the sensor node to interconnect with other sensor nodes. The processing unit is used to allow management and data processing in the sensor node. The function of sensing unit is observing specific phenomenon. The power unit is used to provide the system supply voltage and it can be supported by an energy harvesting unit such as small-scale wind mills or solar cells. Also, it may have optional unit such as mobilize subsystem and location finding system [5, 4, 23]. Therefore, the average energy consumption per unit time of sensor node can be express as:

$$
E=E_{\text {Transciver }}+E_{\text {Processing }}+E_{\text {Sensing }}+E_{\text {Optional }}-E_{\text {Harvest }}
$$

where $E_{\text {Transciver }}, E_{\text {Processing }}, E_{\text {Sensing }}$ and $E_{\text {Optional }}$ are the energy consumption per unit time in transceiver unit, processing unit sensing unit and optional units respectively, and $E_{\text {Harvest }}$ is the energy gained per unit time in harvest unit. In the following we will discuss each main unit individually.

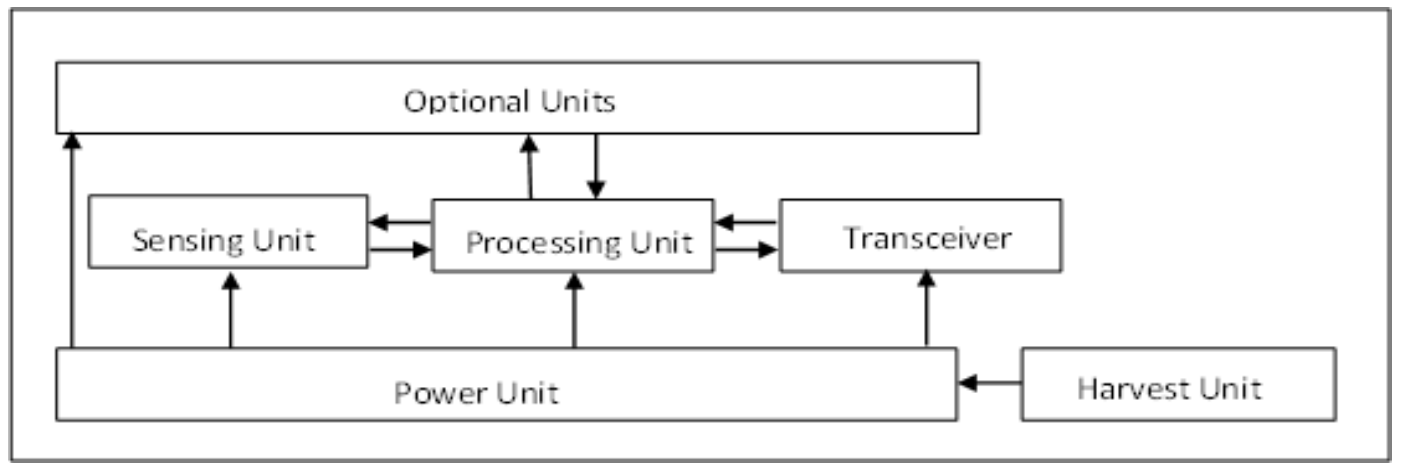

Figure 2. Architecture of Wireless Sensing Node 


\subsection{Transceiver Unit}

The transceiver unit is composed of transmitter circuit, receiver circuit, and an antenna which are used to send and receive packets. The purposes of the transceiver unit are the selection of a frequency channel, a transmit power, the modulation scheme, symbol synchronization, and clock generation [24]. The main components of transceiver at transmitter side are baseband digital circuit, analog transmitted circuit and power amplifier. Similarly the main components of transceiver at receiver side are baseband digital circuit, analog receiver circuit and LNA amplifier [26-28] as shown in Figure 3. The total power consumption for transmitting and for receiving, denoted by $P_{t x}$ and $P_{r x}$, are given by:

$$
\begin{aligned}
& P_{t x}=P_{D c t}+P_{A c t}+P_{a m p}+P_{t}=P_{t o}+(\alpha+1) P_{t} \\
& P_{r x}=P_{D c r}+P_{A c r}+P_{L N A}=P_{r o}
\end{aligned}
$$

where $P_{D c t}$ and $P_{A c t}$ are the power consumptions of the digital circuit at transmitter side and the analog circuit at transmitter side, respectively, the two components can be modeled as a constant, $P_{t o} . P_{a m p}$ and $P_{t}$ are the power consumptions of the power amplifier and transmitted power. $\alpha=\xi / \eta-1$ with $\xi$ and $\eta$ being the drain efficiency and the peak-to-average ratio, respectively. Similarly, $P_{D c r}, P_{A c r}$, and $P_{L N A}$ are the power consumptions of the digital circuit at receiver side, the analog circuit at receiver side, and LNA, respectively, the three components can be modeled as a constant, $P_{r o}$. The characteristics of some of low power transceiver units are summarized in Table 1 [28][30].

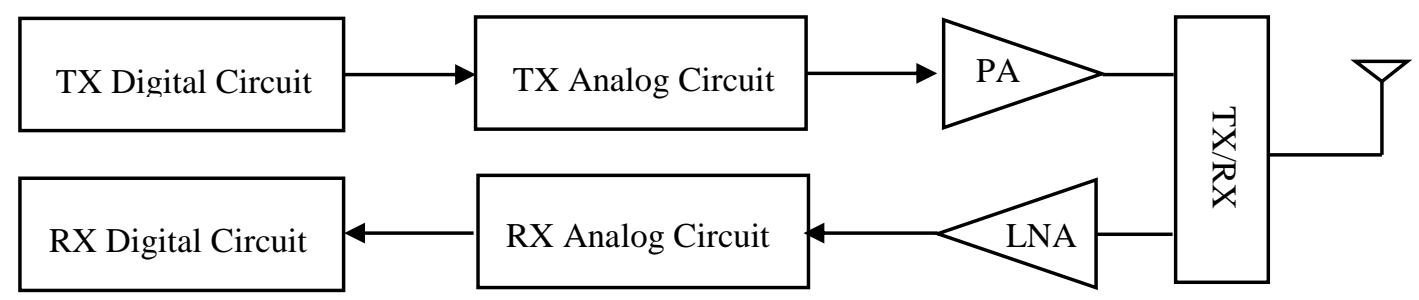

Figure 3. Transceiver Unit Structure

Table 1. Features of Some Current Transceivers

\begin{tabular}{|l|l|l|l|l|l|l|}
\hline \multicolumn{1}{|c|}{ Name } & \multicolumn{1}{|c|}{ Manufacturer } & \multicolumn{1}{c|}{$\begin{array}{c}\text { Band } \\
(\mathrm{MHz})\end{array}$} & $\begin{array}{c}\text { Data rate } \\
(\mathrm{kbps})\end{array}$ & $\begin{array}{c}\text { Sleep } \\
(\mu \mathrm{A})\end{array}$ & $\begin{array}{c}\mathrm{TX} \\
(\mathrm{mA})\end{array}$ & $\begin{array}{c}\mathrm{RX} \\
(\mathrm{mA})\end{array}$ \\
\hline MRF49XA & Microchip & $433 / 868 / 915$ & 256 & .3 & 15 & 11 \\
\hline MRF89XA & Microchip & 915 & 25 & .1 & 25 & 3 \\
\hline MCMRF24J40 & Microchip & 2400 & 250 & 2 & 22 & 18 \\
\hline AT86RF212B & Atmel & $700 / 800 / 900$ & 1000 & .2 & 18 & 9.2 \\
\hline NSnRF2401A & Nordic Semiconductor & 2400 & 1000 & 0.9 & 13.0 & 19.0 \\
\hline NSnRF24L01 & Nordic Semiconductor & 2400 & 2000 & 0.9 & 11.3 & 12.3 \\
\hline NSnRF905 & Nordic Semiconductor & $433-915$ & 50 & 2.5 & 12.5 & 14.0 \\
\hline nRF24L01+ & Nordic Semiconductor & 2400 & 250 & .9 & 11.3 & 13.5 \\
\hline RFMTR1001 & SRFMonolithic & 868 & 115.2 & 0.7 & 12 & 3.8 \\
\hline RFMTR3100 & SRFMonolithic & 433 & 576 & 0.7 & 10 & 7.0 \\
\hline SEXE1201A & Semtech & 433 & 64 & 0.2 & 11.0 & 6.0 \\
\hline SEXE1203F & Semtech & $433-915$ & 152.3 & 0.2 & 33.0 & 14.0 \\
\hline TICC2420 & Texas Instruments & 2400 & 250 & 1 & 17.4 & 18.8 \\
\hline TICC2500 & Texas Instruments & 2400 & 500 & 0.4 & 21.2 & 17.0 \\
\hline TICC1000 & Texas Instruments & $433-915$ & 76.8 & 0.2 & 10.4 & 9.3 \\
\hline
\end{tabular}




\begin{tabular}{|l|l|l|l|l|l|l|}
\hline TICC1100 & Texas Instruments & $433-915$ & 500 & 0.4 & 15.5 & 16.5 \\
\hline TICC2538 & Texas Instruments & 2400 & 250 & 1.3 & 24 & 20 \\
\hline TICC2531 & Texas Instruments & 2400 & 250 & .4 & 29 & 20.5 \\
\hline
\end{tabular}

\subsection{Processing Unit}

The central component of sensor node is processing unit which is used to allow management and data processing in the sensor node. Micro-Controller Unit (MCU) is usually implements the processing unit, which is consist of a micro-processor, memories, and other peripherals [1]. The energy consumption per unit of time for processing unit is given by:

$$
E_{\text {Processing }}=C_{\text {avg }} V_{\text {sub }}^{2} f+V_{\text {sub }}\left(I_{0} e^{\frac{V_{s u b}}{n V_{t}}}\right)
$$

where $C_{a v g}$ is the average capacitance switched per cycle, $V_{\text {sub }}$ is the supply voltage, $V_{t}$ is the thermal voltage, $I_{0}$ is the leakage current, and $f$ is sensor frequency, $n$ is the constant that depends on the processor. The Features of MCUs from several manufacturers are given in Table 2 [1, 28-29].

Table 2. Features of Some MCUs

\begin{tabular}{|l|l|l|l|l|l|}
\hline \multicolumn{1}{|c|}{ Name } & Manufacturer & $\begin{array}{c}\text { SRAM } \\
(\mathrm{kB})\end{array}$ & $\begin{array}{c}\text { FLASH } \\
(\mathrm{kB})\end{array}$ & $\begin{array}{c}\text { 1MIPS } \\
(\mathrm{mA})\end{array}$ & \multicolumn{1}{c|}{$\begin{array}{c}\text { Sleep } \\
(\mu \mathrm{A})\end{array}$} \\
\hline AT89C51RE2 (8051) & Atmel & 8 & 128 & 7.4 & 75 \\
\hline ATmega103L (AVR) & Atmel & 4 & 128 & 1.38 & 1 \\
\hline CY8C29666 & Cypress & 2 & 32 & 10 & 5 \\
\hline M68HC08 & Freescale & 2 & 61 & 3.75 & 22 \\
\hline PIC18LF8722 & Microchip & 3.9 & 128 & 1.0 & 2.32 \\
\hline PIC24FJ128 & Microchip & 8 & 128 & 1.6 & 21 \\
\hline XE8802 (CoolRisc) & Semtech & 1 & 22 & 0.3 & 1.9 \\
\hline MSP430F1611 & Texas Instruments & 10 & 48 & 0.33 & 1.3 \\
\hline
\end{tabular}

\subsection{Sensing Unit}

There are a wide range of low power sensors appropriate for WSNs. Small sensing time, acceptable accuracy and low power consumption are essential requirements for sensing. The energy consumption per unit time in sensing unit at sensor node can be express as [31]:

$$
E_{\text {Sensing }}=\frac{T_{\text {sense }}}{T} b V_{\text {sub }} I_{\text {sense }}
$$

where $I_{\text {sense }}$ is the total current required for sensing activity, $T_{\text {sense }}$ is the sensing time, $T$ is the sensing period, and $\mathrm{b}$ is the number of bit which generate at each activity. The features of some low power sensors are given in Table $3[1,28,32]$ he central component.

\section{Table 3. Features of Some Low Power Sensors}

\begin{tabular}{|l|l|l|l|}
\hline \multicolumn{1}{|c|}{ Name } & \multicolumn{1}{c|}{ Type } & \multicolumn{1}{c|}{ Sensing time } & Active current \\
\hline SLG64-0075 & Liquid-Flow & $30 \mathrm{~ms}$ & $5.1 \mathrm{~mA}$ \\
\hline SFM4100 & Gases- Flow & $4.6 \mathrm{~ms}$ & $12.5 \mathrm{~mA}$ \\
\hline VTISCA3000 & Acceleration & $10 \mathrm{~ms}$ & $120 \mu \mathrm{A}$ \\
\hline VTISCP1000 & Airpressure & $110 \mathrm{~ms}$ & $25 \mu \mathrm{A}$ \\
\hline SensorionSHT15 & Humidity & $210 \mathrm{~ms}$ & $300 \mu \mathrm{A}$ \\
\hline
\end{tabular}




\begin{tabular}{|l|l|l|l|}
\hline AvagoAPDS-9002 & Illumination & $1.0 \mathrm{~ms}$ & $2.0 \mathrm{~mA}$ \\
\hline HitachiHM55B & Magneticfield & $30 \mathrm{~ms}$ & $9.0 \mathrm{~mA}$ \\
\hline FastraxiTRAX03 & Position & $4.0 \mathrm{~s}$ & $32 \mathrm{~mA}$ \\
\hline DallasDS620U & Temperature & $200 \mathrm{~ms}$ & $800 \mu \mathrm{A}$ \\
\hline
\end{tabular}

\subsection{Energy Harvesting Unit}

Due to nature and environment, energy harvesting units don't provide a constant power rate. So, these units are mainly worked in combination with a storage device such as a rechargeable battery or super-capacitor. Storage device stores additional energy and offers it later, when there is no energy can be harvested from the environment. We listed below some common scavenging sources which are used in WSNs [33]:

- Solar cells use light of sun to produce electricity and it are very common energy harvesting sources. Small panel supplies sufficient power to sensor node. A rechargeable battery or a super-capacitor is usually used with solar cells.

- Small- scale wind mills are unusually energy harvesting sources and it appropriate for outdoor applications.

- Radiant energy is harvesting technique that convert energy from electromagnetic waves.

- Vibration energy is harvesting method that convert vibration energy. It common uses with civil engineering applications.

- Thermal energy is harvesting technique that convert the temperature difference between two materials to energy. here are a wide

\subsection{Power Unit}

The power unit stores energy in battery and supply suitable voltage levels. It consists of battery and a voltage regulator [28].

\section{WSNs Platforms}

In recent years, WSNs platforms have improved significantly and many different manufacturers build wireless sensor nodes. Still, because of the severe energy constrains, the current level of technology can't achieve all the requirements. In general, This platforms are classified into three categories, each of which shows diverse hardware setup commensurate with varied applications [9].

- Adapted General-Purpose Computers: are low power embedded PCs, tablet PCs, and smart phones. It generally run on operating system such as Windows, Mac OS, Linux, and Android. These platforms are mainly work with wireless communications standards such as GSM, UMTS, LTE, Bluetooth, and wireless LAN. These platforms are programmed using higher level programming languages such as Java and $\mathrm{C}++$, which makes develop and implement software components more easy.

- Embedded Sensor Modules: are grouped from different chips such as MCU and transceiver. Due to mass production of these chips, the cost of these categories is cheap and widely used. $\mathrm{C} / \mathrm{C}++$ is generally used to program the MCUs of these platforms. Examples of this category include Mica, Mica2Dot, and WeC.

- System on chip (SoC): is one chip contain transceiver, sensors, and the MCU. These platforms have a small size and low energy consumption. Examples of this category include smart dust node and PASTA node. 
Nowadays, quite a few platforms for WSNs are available. This diverse group of these platforms give the option to select a platform which fits with the requirements of the applications. The characteristics of some sensor platforms are presented in Table 4 [9, 32-34].

\section{Communication Protocols}

In WSNs, there are five communication layers: physical layer, data link layer, network layer, transport layer, and application layer as shown in Figure 4 [37]. In the following, we discuss the most significant features of each communication layer.

\begin{tabular}{|c|}
\hline Application Layer \\
\hline Transport Layer \\
\hline Network Layer \\
\hline Data-link Layer \\
\hline Physical Layer \\
\hline
\end{tabular}

Figure 4. Sensor Network Architecture

Table 4. The Characteristics of Some Sensor Platforms

\begin{tabular}{|c|c|c|c|c|}
\hline $\begin{array}{l}\text { Platforms } \\
\text { Name }\end{array}$ & Microcontroller & Transceiver & $\begin{array}{l}\text { Program + Data } \\
\text { Memory }\end{array}$ & Programming \\
\hline KMote & TI MSP430 & $\begin{array}{c}250 \mathrm{kbit} / \mathrm{s} 2.4 \mathrm{GHz} \text { IEEE 802.15.4 } \\
\text { Chipcon Transceiver }\end{array}$ & $\begin{array}{l}10 \mathrm{~KB} \text { RAM } \\
48 \mathrm{~KB} \text { flash }\end{array}$ & $\begin{array}{l}\text { TinyOS and SOS } \\
\text { Support }\end{array}$ \\
\hline NeoMote & ATmega 128L & $\begin{array}{c}\text { TI CC2420 802.15.4/ZigBee } \\
\text { compliant radio }\end{array}$ & $\begin{array}{l}4 \mathrm{~KB} \text { RAM } \\
128 \mathrm{~KB} \text { flash }\end{array}$ & $\begin{array}{c}\text { TinyOS and SOS } \\
\text { Support }\end{array}$ \\
\hline PowWow & MSP430F1612 & $\begin{array}{c}\text { TI CC2420 802.15.4/ZigBee } \\
\text { compliant radio }\end{array}$ & $\begin{array}{l}5 \mathrm{~KB} \text { RAM } \\
55 \mathrm{~KB} \text { flash }\end{array}$ & $\mathrm{C} / \mathrm{C}++$ \\
\hline TelosB & TI MSP430 MCU & $\begin{array}{l}250 \mathrm{kbit} / \mathrm{s} 2.4 \mathrm{GHz} \text { IEEE } 802.15 .4 \\
\text { Chipcon Transceiver }\end{array}$ & $\begin{array}{l}5 \text { KB RAM } \\
48 \text { KB flash }\end{array}$ & $\begin{array}{c}\text { TinyOS and SOS } \\
\text { Support }\end{array}$ \\
\hline panStamp & Atmega328P & TI CC1101 (868/915 MHz) & $\begin{array}{l}2 \mathrm{~KB} \text { RAM } \\
32 \mathrm{~KB} \text { flash }\end{array}$ & $\mathrm{C} / \mathrm{C}++$ \\
\hline Ubimote2 & TI's MSP430F2618 & $\begin{array}{c}\text { TI's CC2520 } 2.4 \mathrm{GHz} \text { ZigBee®/ } \\
\text { IEEE 802.15.4 }\end{array}$ & $\begin{array}{l}8 \mathrm{~KB} \text { RAM } \\
116 \mathrm{~KB} \text { flash }\end{array}$ & $\mathrm{C} / \mathrm{C}++$ \\
\hline Mica & $\begin{array}{c}\text { ATmega } 103-4 \\
\text { MHz 8-bit }\end{array}$ & RFM TR 1000 radio 50 kbit/s & $\begin{array}{l}4 \mathrm{~KB} \text { RAM } \\
128 \mathrm{~KB} \text { flash }\end{array}$ & TinyOS Support \\
\hline Mica2 & ATMEGA 128L & Chipcon 868/916 MHz & $\begin{array}{l}4 \text { KB RAM } \\
128 \text { KB flash }\end{array}$ & $\begin{array}{l}\text { TinyOS and SOS } \\
\text { Support }\end{array}$ \\
\hline XYZ & ML67 series MCU & $\begin{array}{c}\text { TI CC2420 802.15.4/ZigBee } \\
\text { compliant radio }\end{array}$ & $\begin{array}{l}32 \mathrm{~KB} \text { RAM } \\
256 \mathrm{~KB} \text { flash }\end{array}$ & $\mathrm{C} / \mathrm{C}++$ \\
\hline FireFly & $\begin{array}{c}\text { Atmel ATmega } \\
1281\end{array}$ & Chipcon CC2420 & $\begin{array}{l}8 \mathrm{~KB} \text { RAM } \\
128 \mathrm{~KB} \text { flash }\end{array}$ & $\mathrm{C} / \mathrm{C}++$ \\
\hline
\end{tabular}

\subsection{Physical Layer}

Physical layer is the lower layer of the communication layers and it provides the interface to the sensor node to communicate with other node over the physical medium. The function of physical layer is carrier frequency generation, modulation, and signal detection. In WSNs, the physical layer should be given a special care due to the characteristic constraints, such as low-power consumption and hardware design, such as low-power consumption and hardware design [35]-[36]. 


\subsection{Data-link Layer}

The second layer of the communication stack is Data link layer (DLL) and it generally consist of two sub-layers: Logical Link Control (LLC) and Medium Access Control (MAC). In the following, we will only discuss the MAC sub-layer, because it has high important effects on the energy consumption and latency issues $[1,38]$. The functions of MAC protocols are providing connections for the routing protocol and managing transceiver unit on a shared wireless medium. In general, there are two categories of MAC protocols [8, 39-40]:

1) Schedule-based Protocols which is depend on scheduling and reservation. Time-division multiple access (TDMA) is a good example of these type of protocols, in which the time is divided into several time slots. Each time slot is assigned to a sensor node and a node can transfer message during its assigned time.

2) Contention-Based MAC Protocols, in which nodes compete to reserve shared wireless media and trying to avoid packet collisions. In this type of MAC protocols, duty cycling is used to advanced energy saving, where the time is divided into a long sleep period and a small active period. This type of MAC protocols can be classified, according to the synchronization of data exchanged, into two categories: unsynchronized and synchronized protocols as shown in Figure 5, [41-42].

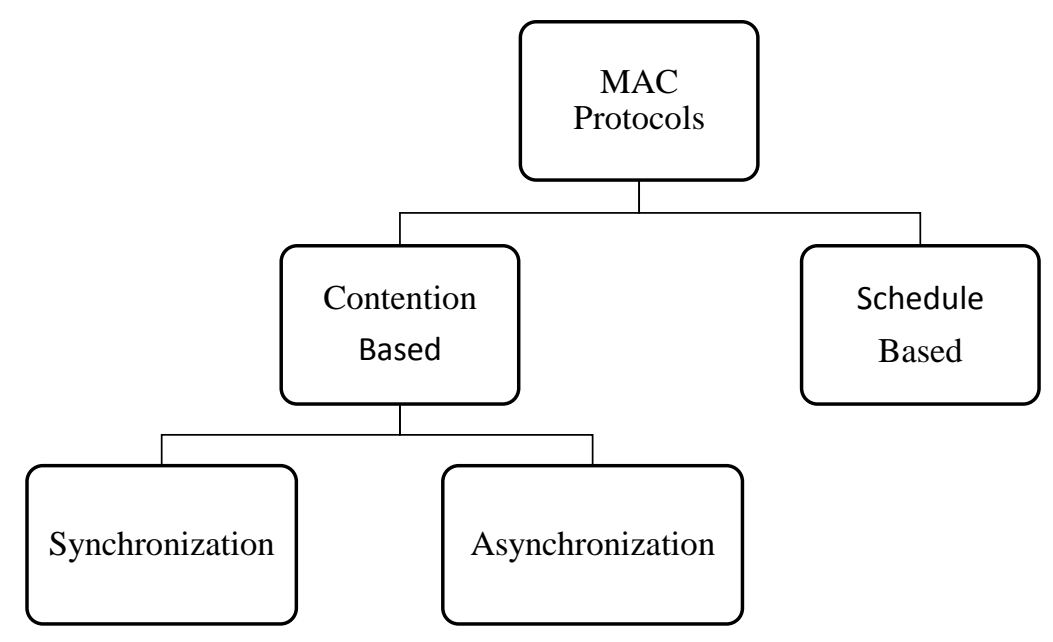

Figure 5. Category of MAC Protocols

5.2.1. Unsynchronized low Duty-Cycle MAC protocols: Duty cycling mechanism is used in unsynchronized low duty-cycle MAC protocols where notes listening to physical medium asynchronously to check for any probable flow [41, 43]. Example of an unsynchronized MAC protocol is presented in Figure 6. In this MAC protocol example, transmissions are start with a Request to Send (RTS) preamble packet. If the destination is in active state and receives the RTS preamble packet, it sends a Clear to Send (CTS) packet. Then the source will transmit a data packet. If the destination is in a sleep state when source send an RTS packet, then the RTS preamble packet works as a wake-up signal and the source will repeat attempts to retransmit the RTS packet, after going into a power saving period for a short time, until the destination wakes up and receives the RTS packet.

5.2.2. Synchronized low Duty-Cycle MAC protocols: Scheduling mechanism is used in synchronized low duty-cycle MAC protocols to ensure that sensor nodes approve 
the packet exchange. Because of the synchronization, each node knows the time of active periods of other nodes, so no need of long preambles or resend preambles $[41,44]$. The synchronization is usually made by receiving a synchronization packet, which includes synchronization information, from surround nodes, as shown in Figure 7. Then, nodes exchange data packets during the active period which is followed by a sleep period to reduce energy consumption.

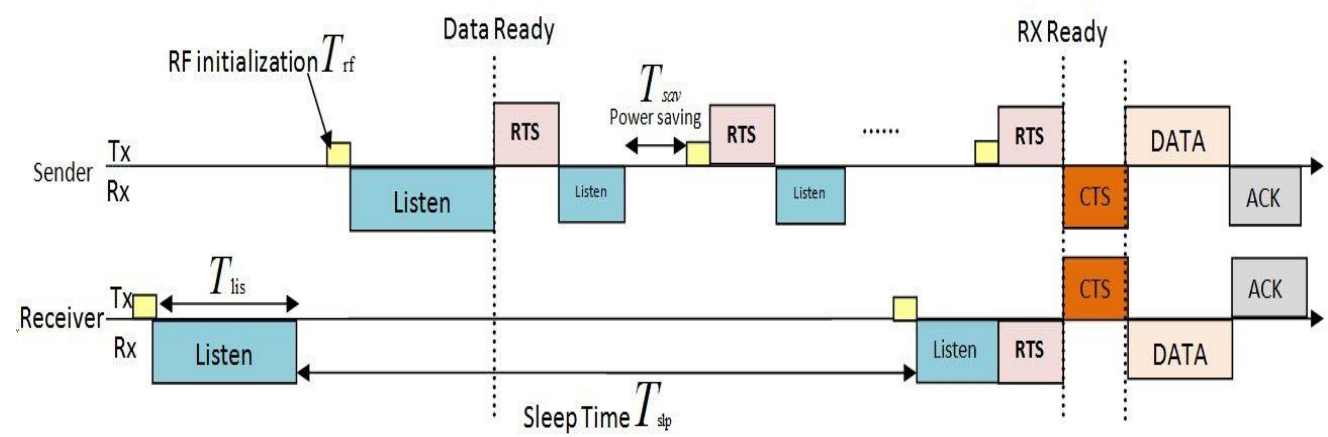

Figure 6. Time Diagram for Asynchronies MAC Protocols

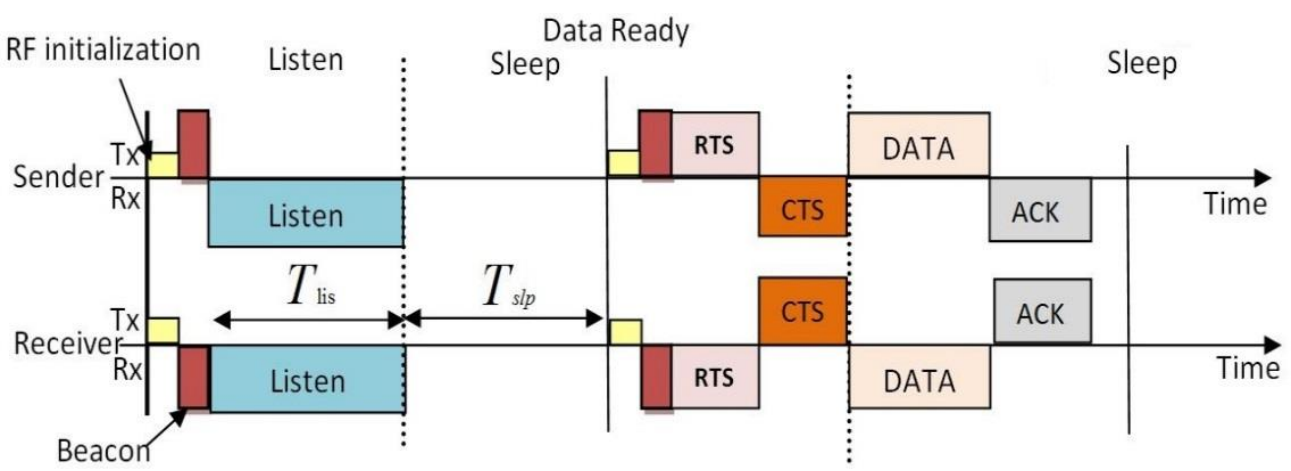

Figure 7. Time Diagram for Synchronies MAC Protocols

\subsection{Network Layer}

The third layer in the WSNs communication protocol stack is the network layer. The functions of network layer are network routing, error control, source to destination packet delivery, network segmentation and de-segmentation, and flow control [1,38]. In WSNs, finding the route between a source node and destination node is task of the routing protocols. Based on the operation of WSNs routing protocols, it can be categorized into: node-centric, data-centric, location based, multipath routing, hierarchical protocols, mobility-based protocols, and QoS-based protocols as shown in Figure 8. All of these categories are not limited as a routing protocol may be node-centric and having features in QoS-based Protocols [45-46]. We listed below characteristics and features of these protocols and provide some example of routing protocols for each category in Table 5.

- Node-centric Approach: uses routing tables for routing process and each node is addressed with a unique identifier. Due to the large network size, the condition of unique addressing is more complex in WSNs. There are two techniques to create the routing table; proactively and on-demand (reactive). In proactively, the routing table in this type of routing protocols is created by determining paths to all possible targets such as such as Dynamic Source 
Routing (DSR). In on-demand, the routes are created only when required such as Ad-hoc On-demand Distance Vector routing (AODV) [1].

- Data centric routing: the content of message is used to determine the routes instead of using node identifiers so it more compatible for WSNs than the node-centric protocols. This type of routing protocols can be categorized into three categories; negotiation based, interest based, and query based approaches. In negotiation-based protocols, data transmission takes place after exchange negotiation messages. During the negotiation phase, a node can decide that the data is not wanted so this reduces energy consumption. In the interest based protocols, a sink node request data from each node in the network by transferring a request telling the data it needs then nodes forward the required data to the sink node. In query based approaches, high level language such as database program might be used to express a query. For example, a query might request average humidity or pressure in specific region during a period of time [45].

- Location-based routing: in which the routing decisions is made based on geographical position. A basic principle operation of location-based routing protocols is to choose a next hop which is nearest to the target node [6].

- Multipath routing: that aims to increase reliability by transmitting a message from a source node to a destination node through several paths [2], [6]. The power unit stores energy in battery and supply suitable voltage levels. It consists of battery and a voltage regulator [28].

- Hierarchical Routing: is a method of routing in WSNs that is based on breaks the WSN into clusters. Each cluster consist of group of nodes and cluster head, which is responsibility of exchange data from the cluster to the other cluster heads. [2].

- Mobility-based Routing: used to serve WSN with mobile nodes and mobility in WSNs generates new challenges to routing protocols [45].

- QoS-based Routing: is the routing protocols which consider QoS requirements in terms of latency, fault tolerance, and reliability in routing decision $[2,6,45]$.

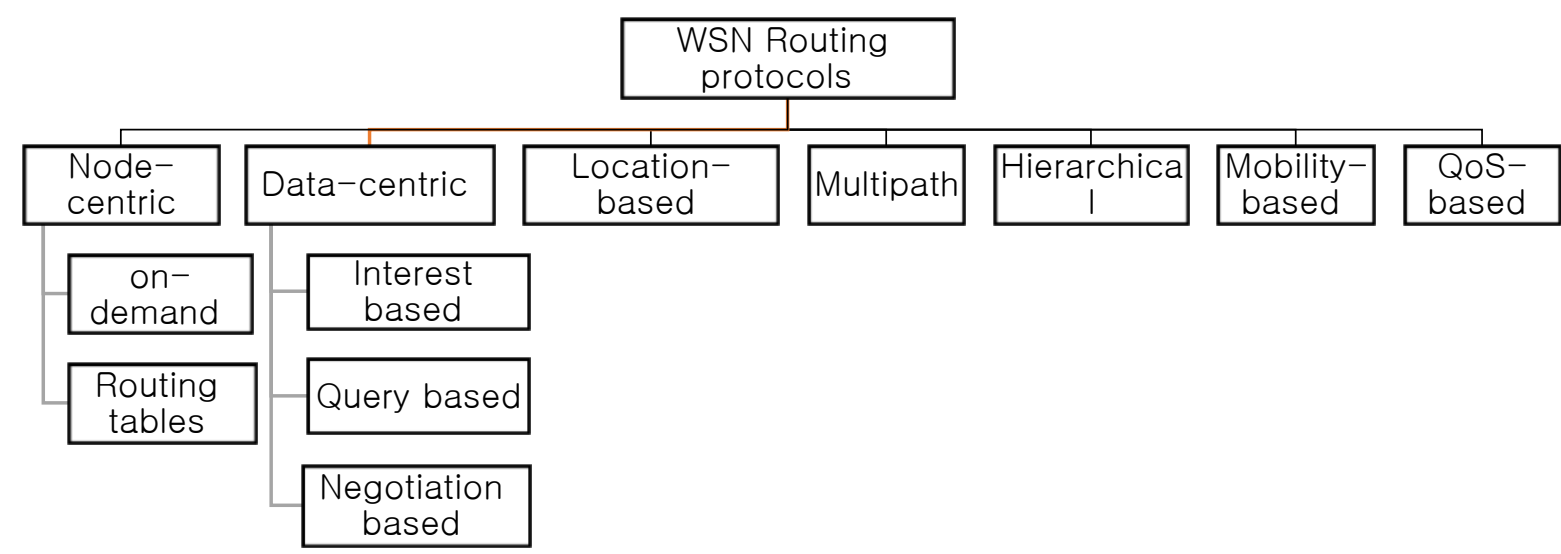

Figure 8. WSNs Routing Protocols

\subsection{Transport Layer}

The fourth layer in the WSN communication protocol stack is the transport layer. It provides services such as flow control, multiplexing and reliability between end 
users [47]. The power unit stores energy in battery and supply suitable voltage levels. It consists of battery and a voltage regulator [28].

\subsection{Application Layer}

The last layer of the WSN communication protocol stack is the application layer and it makes common services for the application. The Sensor Management Protocol (SMP), and the Sensor Query and Data Dissemination Protocol (SQDDP) are examples of application protocols in WSNs [5, 47].

Table 5. Routing Protocols in WSNs

\begin{tabular}{|l|l|}
\hline \multicolumn{1}{|c|}{ Category } & \multicolumn{1}{c|}{ Protocols } \\
\hline Node-centric Routing & AODV, DSR \\
\hline Location-based Protocols & BVGF, TBF, GeRaF, Span, GEAR, GAF, SMECN, MECN \\
\hline Data-centric Protocols & $\begin{array}{l}\text { Home Agent Based Information Dissemination, Quorum-Based } \\
\text { Information Dissemination, Energy-aware Routing, Information- } \\
\text { Directed Routing, SPIN, Information-Directed Routing Directed } \\
\text { Diffusion, Energy-aware Routing, Rumor Routing, Gradient } \\
\text { Based Routing, COUGAR, ACQUIRE, EAD, Information- } \\
\text { Directed Routing, Gradient Based Routing }\end{array}$ \\
\hline Hierarchical Protocols & APTEEN, HEED, LEACH, TEEN, PEGASIS \\
\hline Mobility-based Protocols & Data MULES, SEAD, Joint Mobility and Routing, TTDD \\
\hline $\begin{array}{l}\text { Multipath-based } \\
\text { Protocols }\end{array}$ & $\begin{array}{l}\text { N-to-1 Multipath Discovery, Sensor-Disjoint Multipath, Braided } \\
\text { Multipath }\end{array}$ \\
\hline QoS-based protocols & Energy-aware routing, SPEED, SAR \\
\hline
\end{tabular}

\section{Simulation Programs of WSNs}

WSNs consists of a high number of sensing nodes, which is used to monitor and study phenomena and providing information that was not available before in places which are difficult to reach. It is hard to build a WSN model analytically and it usually leads to oversimplified analysis with limited accuracy. Therefore, simulation is essential to study WSN and it requires a suitable model based on accurate assumptions. Simulation provides exact environmental settings for calculating and improving the design factors. It also provides great vision about the effects of the different factors. The available simulator programs are mostly developed in $\mathrm{C}++$ or Java and it are either open source or commercial as shown in Figure 9 [47]. The features and comparison of each of these WSN simulating tools are given in Table 6.

\subsection{Commercial Simulators}

There are a little number of commercial simulators tools such as OPNET, QualNet and NetSim which are able to simulate, in real-time, a big number of nodes. Due to cost reasons, commercial simulator programs may not be the good choice for researchers. We listed below characteristics and features of some commercial sensor network simulators:

- OPNET Modeler Wireless Suite is a simulation tool and modeling for different kinds of wireless networks. It is developed by OPNET Technologies, Inc. and based on the familiar product OPNET Modeler [48], [49]. 
- QualNet is network emulation and simulation and it enables real-time network simulation. It is provided by Scalable Networks Technologies, Inc. and it has ability to deal with real networks and other simulations [50].

- NetSim is a state-of-the-art network simulator for lab experimentation, R\&D. Several technologies such as Wireless LAN, WSNs, Wi Max, IP, TCP, etc., are covered in NetSim. It allow researchers in WSNs topic to simulate energy efficient and power management, efficient protocol design, self-configuration, routing, localization, LEACH etc., [51].

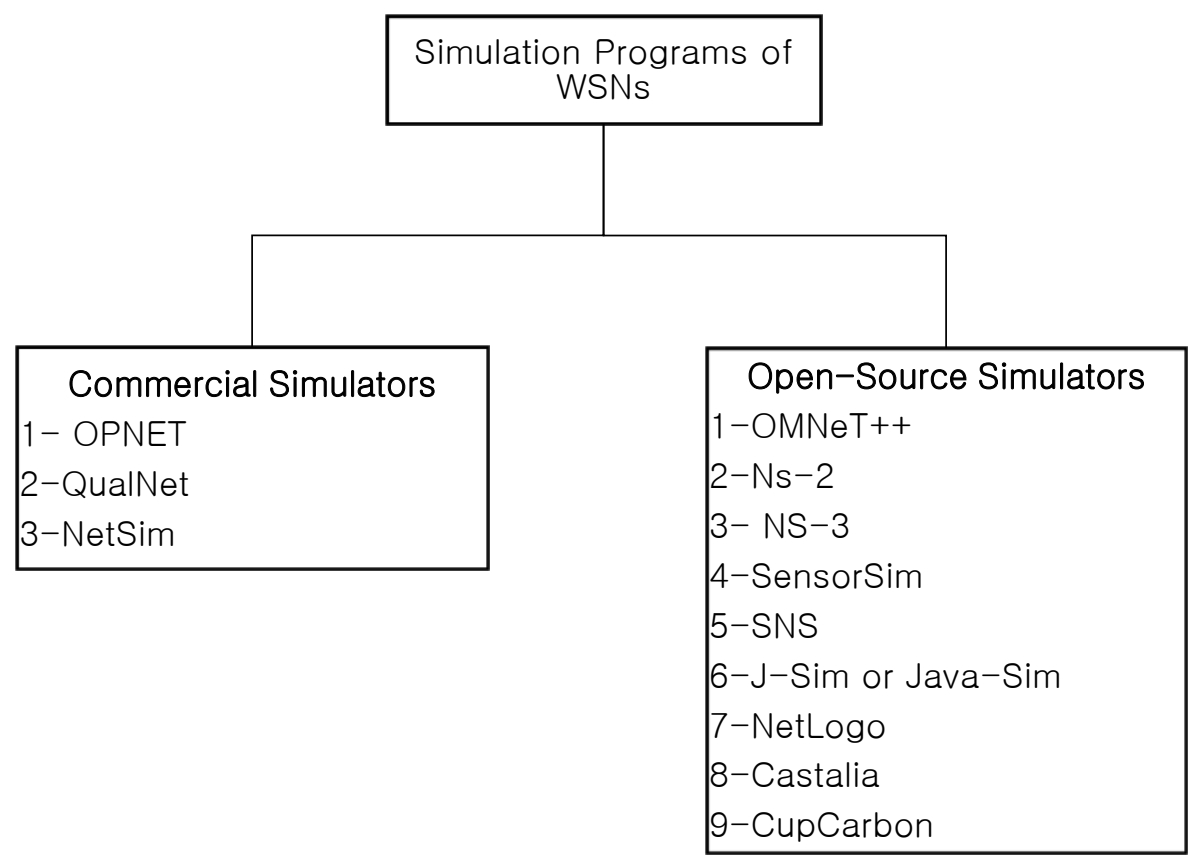

Figure 9. Simulation Programs of WSNs

\subsection{Open-Source Simulators}

Open-Source or Academic simulators are often suitable to help with research projects and some of them under development. We listed below characteristics and features of the most relevant academic WSNs simulators:

- OMNeT++ is an extensible, modular, component-based $\mathrm{C}++$ simulation library and framework, primarily for building network simulators. It can be run on the most common operating systems such as Mac OS, Windows, and Linux. There are some frameworks which enable OMNeT++ to be used for WSNs such as Mixim [48, 52].

- Ns-2 "is a discrete event simulator targeted at networking research which provides support for MAC and routing, protocols, among many others. It supports simulation for wireless and mobile network and it provides various modules for mobile WSNs. There are some simulation frameworks that enable Ns-2 to simulate WSNs such MannaSim [48, 53].

- Ns-3 "is a discrete-event network simulator, targeted primarily for research and educational use. Ns-3 is free software, licensed under the GNU license, and is publicly available for research, development, and use NS-3 is not an extension of NS-2; it is a new simulator". The recent version NS-3.13 was released on 17 September 2014 [54]. 
Table 6. Comparison between Different Wireless Sensor Simulation Programs

\begin{tabular}{|c|c|c|c|c|c|}
\hline No & Simulator & Operation system & $\begin{array}{c}\text { Programming } \\
\text { language }\end{array}$ & Type & Recent version \\
\hline 1 & OPNET & windows/Linux & C/C++ & Commercial & 9.1 \\
\hline 2 & QualNet & windows/Linux & C/C++ & Commercial & 5.2 \\
\hline 3 & NetSim & windows & C/C++ and Java & Commercial & 8 \\
\hline 4 & OMNeT++ & windows/Linux & C/C++ and Java & Open Source & 4.5 \\
\hline 5 & Ns-2 & Linux & C/C++ & Open Source & 2.35 \\
\hline 6 & Ns-3 & Linux & C/C++ & Open Source & 3.21 \\
\hline 7 & SensorSim & Linux & C/C++ & Open Source & 1 \\
\hline 8 & J-Sim & windows/Linux & Java & Open Source & 1.3 \\
\hline 9 & NetLogo & windows/Linux & Java & Open Source & 5.1 .0 \\
\hline 10 & Castalia & Linux & C/C++ & Open Source & 3.2 \\
\hline 11 & CupCarbon & windows/Linux & Java & Open Source & 1 \\
\hline
\end{tabular}

- SensorSim is provided by the University of California at Los Angeles (UCLA). It has additional extended Ns-2 by including support for WSNs simulation. Also, it includes the definition of sensor node, and sink nodes, a mobility model, wireless communication channels, physical media, and a power model [55].

- J-Sim or Java-Sim is open-source component-based framework for WSNs simulation. It includes the definition of sensor nodes, target, and sink nodes, a mobility model, wireless communication channels, physical media, and a power model [48].

- NetLogo "is a simulation of data dissemination flooding technique in wireless sensor network. Such a network is used to detect and report certain events across an expanse of a remote area - e.g., a battlefield sensor network that detects and reports troop movements. The idea behind this network is that it can be deployed simply by scattering sensor units across the area, e.g., by dropping them out of an airplane; the sensors should automatically activate, self-configure as a wireless network with a mesh topology" [56].

- Castalia "is a WSNs simulator for early-phase algorithm/protocol testing built at the Networks and Pervasive Computing program of National ICT Australia. It supports realistic channel and radio models, a key element for accurate early-phase WSN simulation. It provides support for defining versatile physical processes. It also supports enhanced modeling of the sensing devices and other often-neglected attributes of a WSN such as node clock drift". The recent version Castalia 3.2 was released on 30 March 2011 [57].

- CupCarbon is a multi-agent and discrete event WSN simulator. Networks can be designed and prototyped in an ergonomic user-friendly interface using the Open-Street-Map (OSM) framework by deploying sensors directly on the map. It can be used to study the behavior of a network and its costs. 
The sensors are composed of a microcontroller, a battery, an antenna and a sensor unit. The main objectives of CupCarbon are both educational and scientific. It can help trainers to explain the basic concepts and how sensor networks work and it can help scientists to test their wireless topologies, protocols, etc., [58].

\section{Conclusion}

At present, WSNs are a hot research topic and it has increasingly improved the way to monitor industrial phenomenon and environmental over the last two decades. In this article, a wide survey of the recent state of the art about WSNs, the concept, definition and applications, is provided. Also, an overview of WSNs constrains and judgment metrics such as lifetime and latency is given. Furthermore, a wide review of existing hardware and platforms of WSNs is provided. To fully understanding of WSNs, comprehensive description of the communication protocol stack, which include five layers; physical layer, data link layer, network layer, transport layer, and application layer, is given. Moreover, WSNs MAC protocols is classify into two categories: contention-based and schedule-based MAC protocols. Also, contentionBased MAC protocols is classify into two categories: asynchronous and synchronous. This classification aims to identify the research trend of WSN MAC protocols based on methods they use. Moreover, in this article, the routing techniques are categorized based on their operation as node-centric, data-centric, location based, multipath routing, hierarchical protocols, mobility-based protocols, and QoS-based protocols. Finally, to help researchers and designers to selecting a suitable simulation, a wide review of current simulation programs is provided.

\section{References}

[1] J. Suhonen, M. Kohvakka, V. Kaseva, T. D.Hämäläinen and M. Hännikäinen, "Low-power Wireless Sensor Networks: Protocols, Services and Applications. Springer, (2012).

[2] J. N. Al-Karaki and A. E. Kamal, "Routing techniques in wireless sensor networks: a survey", IEEE Wirel. Commun., vol. 11, no. 6, (2004) December, pp. 6-28.

[3] M. A. E. Villegas, "An Energy-Efficient Mac Protocol for Wireless Sensor Networks for Wide Area Large Scale Environmental Monitoring”, University of Puerto Rico Mayagüez Campus, (2006).

[4] J. Yick, B. Mukherjee and D. Ghosal, "Wireless sensor network survey", Comput. Networks, vol. 52, no. 12, (2008) August, pp. 2292-2330.

[5] I. F. Akyildiz, W. Su, Y. Sankarasubramaniam and E. Cayirci, "Wireless sensor networks : a survey", Comput. networks, vol. 38, (2002), pp. 393-422.

[6] K. Akkaya and M. Younis, "A survey on routing protocols for wireless sensor networks", Ad Hoc Networks, vol. 3, no. 3, (2005), pp. 325-349.

[7] A. Koubâa, M. Alves and E. Tovar, "Lower Protocol Layers for Wireless Sensor Networks: A Survey", IPP-Hurray Gr., (2005) November.

[8] C. Chen, C. Weng and C. Ku, "Design of a low power and low latency MAC protocol with node grouping and transmission pipelining in wireless sensor networks", Comput. Commun., vol. 31, (2008), pp. 3725-3738.

[9] F. Zhao and L. J. Guibas, "Wireless sensor networks: an information processing approach", Morgan Kaufmann, (2004).

[10] T. Laukkarinen, J. Suhonen and M. Hännikäinen, "A Survey of Wireless Sensor Network Abstraction for Application Development”, Int. J. Distrib. Sens. Networks, vol. 2012, (2012), pp. 1-12.

[11] Y. Li, M. T. Thai and W. Wu, "Wireless Sensor Networks and Applications", Springer, (2008).

[12] S. Misra, I. Woungang and S. Chandra Misra, "Guide toWireless Sensor Networks", Springer, (2009).

[13] S. Yoon, "Powe Mangment in Wirelesss Sensor Networks", North Carolina State University, (2007).

[14] W. Zeng, "Topics in Energy Efficiency of Low-Power Wireless Sensor Networks", Ohio State University, (2012).

[15] Y. Chen, S. Member and Q. Zhao, "On the Lifetime of Wireless Sensor Networks", IEEE Commun. Lett., vol. 9, no. 11, (2005), pp. 976-978.

[16] M. Ye, C. Li, G. Chen and J. Wu, "An Energy Efficient Clustering Scheme in wireless sensor networks", Performance, Comput. Commun. Conf. 2005. IPCCC 2005. 24th IEEE Int. IEEE, vol. 3, (2006), pp. 99119. 
[17] J. Ammer and J. Rabaey, "The Energy-per-Useful-Bit Metric for Evaluating and Optimizing Sensor Network Physical Layers”, Sens. Ad Hoc Commun. Networks, 2006. SECON'06. 2006 3rd Annu. IEEE Commun. Soc., vol. 2, (2006), pp. 1-6.

[18] Y. Wang, M. C. Vuran and S. Goddard, "Cross-Layer Analysis of the End-to-End Delay Distribution in Wireless Sensor Networks”, IEEE/ACM Trans. Netw., vol. 20, no. 1, (2012) February, pp. 305-318.

[19] S. Ehsan, B. Hamdaoui and M. Guizani, "Radio and Medium Access Contention Aware Routing for Lifetime Maximization in Multichannel Sensor Networks", IEEE Trans. Wirel. Commun., vol. 11, no. 9 , (2012) September, pp. 3058-3067.

[20] H. Jaleel, S. Member, and A. Rahmani, "Probabilistic Lifetime Maximization of Sensor Networks", IEEE Trans. Automat. Contr., vol. 58, no. 2, (2013).

[21] E. P. Allocation, M. Hajiaghayi, S. Member, M. Dong, S. Member and B. Liang, "Maximizing Lifetime in Relay Cooperation Through,” IEEE Trans. Signal Process., vol. 58, no. 8, (2010), pp. 4354-4366.

[22] W. Huang, S. Member, Y. P. Hong and C. J. Kuo, "Lifetime Maximization for Amplify-and-Forward Cooperative Networks", IEEE Trans. Wirel. Commun., vol. 7, no. 5, (2008), pp. 1800-1805.

[23] A. Murtala, L. Ang and K. Phooi, "Classical and swarm intelligence based routing protocols for wireless sensor networks : A survey and comparison”, Netw. Comput. Appl., vol. 35, no. 5, (2012), pp. 15081536.

[24] C. Ceken, "An energy efficient and delay sensitive centralized MAC protocol for wireless sensor networks", Comput. Stand. Interface, vol. 30, (2008), pp. 20-31.

[25] O. Amin, S. Bavarian and L. Lampe, "Cooperative Techniques for Energy-Efficient Wireless Communications", Green Radio Communication Networks, (2012), pp. 125-151.

[26] Q. Wang, M. Hempstead and W. Yang, "A Realistic Power Consumption Model for Wireless Sensor Network Devices", 2006 3rd Annu. IEEE Commun. Soc. Sens. Ad Hoc Commun. Networks, (2006), pp. 286-295.

[27] T. Wang, W. Heinzelman and A. Seyedi, "Minimization of Transceiver Energy Consumption in Wireless Sensor Networks with AWGN Channels", Communication, Control, and Computing, 2008 46th Annual Allerton Conference on. IEEE, (2008), pp. 62-66.

[28] M. Kohvakka, "Medium Access Control and Hardware Prototype Designs for Low-Energy Wireless Sensor Networks", Tampereen teknillinen yliopisto. Julkaisu-Tampere University of Technology. Publication; 808, (2009).

[29] "Microchip Corporation." [Online]. Available: http://www.microchip.com/. [Accessed: 12-Oct-(2014)].

[30] “RF Transceiver." [Online]. Available: http://www.nordicsemi.com/. [Accessed: 12-Oct-(2014)].

[31] M. N. Halgamuge, M. Zukerman, and K. Ramamohanarao, "An Estimation of Sensor Energy Consumption,” Prog. Electromagn. Res. B, vol. 12, (2009), pp. 259-295.

[32] "Sensirion AG." [Online]. Available: http://www.sensirion.com. [Accessed: 12-Oct-(2014)].

[33] R. Bischoff, J. Meyer, and G. Feltrin, "Wireless Sensor Network Platforms", Encycl. Struct. Heal. Monit., (2009), pp. 1-10.

[34] A.-B. García-Hernando, J.-F. Martínez-Ortega, J.-M. López-Navarro, A. Prayati and L. Redondo-López, Eds., "Hardware Platforms for WSNs", Problem Solving for Wireless Sensor Networks, London: Springer London, (2008).

[35] M. Leopold, "Sensor Network Motes:: Portability \& Performance," University of Copenhagen, (2008).

[36] "SNM-The Sensor Network Museum.” [Online]. Available: http://www.snm.ethz.ch/. [Accessed: 08Oct-(2014)].

[37] A. Abed, A. Alkhatib and G. S. Baicher, "Wireless Sensor Network Architecture", International Conference on Computer Networks and Communication Systems, vol. 35, no. Cncs, (2012), pp. 11-15.

[38] W. Sensor, Wireless Sensor Networks A Networking Perspective. John Wiley \& Sons, (2009).

[39] S. A. Malik, M. Asif, A. H. Dar, M. A. Shah and S. A. Khan, "Analysis of Contention Based Medium Access Control Protocols for Wireless Sensor Networks", Aust. J. Basic Appl. Sci., vol. 4, no. 10, (2010), pp. 5473-5482.

[40] Z. Rezaei and S. Mobininejad, "Energy Saving in Wireless Sensor Networks", Int. J. Comput. Sci. Eng. Surv., vol. 3, no. 1, (2012), pp. 23-37.

[41] P. Huang, L. Xiao, S. Member, S. Soltani, S. Member, M. W. Mutka and N. Xi, "The Evolution of MAC Protocols in Wireless Sensor Networks: A Survey”, IEEE Commun. Surv. Tutorials, vol. 15, no. 1, (2013), pp. 101-120.

[42] K. Nguyen and Y. Ji, "Asynchronous MAC Protocol with QoS Awareness in Wireless Sensor Networks," in Globecom 2012 - Ad Hoc and Sensor Networking Symposium Asynchronous, (2012), pp. 573-577.

[43] B. Jang, J. Bum and M. L. Sichitiu, "An asynchronous scheduled MAC protocol for wireless sensor networks", Comput. Networks, vol. 57, no. 1, (2013), pp. 85-98.

[44] M. Doudou, D. Djenouri, N. Badache and A. Bouabdallah, "Synchronous contention-based MAC protocols for delay-sensitive wireless sensor networks : A review and taxonomy", Netw. Comput. Appl., vol. 38, (2013), pp. 1-13.

[45] S. K. Singh, M. P. Singh and D. K. Sing, "Routing Protocols in Wireless Sensor Networks -", Int. J. Comput. Sci. Eng. Surv., vol. 1, no. 2, (2010), pp. 63-83. 
[46] S. Kumar, A. Kumar and R. kumar Vishwkarma, "A Survey on Routing Protocol for Wireless Sensor Network”, Int. J. Adv. Res. Comput. Eng. Technol., vol. 2, no. 2, (2013), pp. 750-755.

[47] A.-B. Garcia-Hernando, J. Fernan, M. Ortega, J. Manuel, L. Navarro, A. Prayati and L. Redondo-Lopez, "Problem Solving for Wireless Sensor Networks", Springer-Verlag London, (2008).

[48] Q. I. Ali, "Simulation Framework of Wireless Sensor Network (WSN ) Using MATLAB / SIMULINK Software", (2012), pp. 263-284.

[49] “OPNET Technologies, Inc." [Online]. Available: http://www.opnet.com/. [Accessed: 08-Oct-(2014)].

[50] "SCALABLE Network Technologies, Inc." [Online]. Available: http://web.scalablenetworks.com/content/qualnet. [Accessed: 08-Oct-(2014)].

[51] T. Company., "NetSim." [Online]. Available: http://www.tetcos.com/index.html. [Accessed: 08-Oct(2014)].

[52] "OMNeT++ Community." [Online]. Available: http://www.omnetpp.org/ . [Accessed: 08-Oct-(2014)].

[53] “The Network Simulator - ns-2." [Online]. Available: http://www.isi.edu/nsnam/ns/. [Accessed: 08-Oct(2014)].

[54] "NS-3 Network simulator", [Online]. Available: http://www.nsnam.org/. [Accessed: 08-Oct-(2014)].

[55] "SensorSim Network simulator", [Online]. Available: http://nesl.ee.ucla.edu/projects/sensorsim/. [Accessed: 08-Oct-(2014)].

[56] "NetLogo Network simulator." [Online]. Available: http://ccl.northwestern.edu/netlogo/. [Accessed: 08Oct-(2014)].

[57] “Castalia Network simulator." [Online]. Available: https://castalia.forge.nicta.com.au. [Accessed: 08Oct-(2014)].

[58] "CupCarbon network simulator." [Online]. Available: http://www.cupcarbon.com. [Accessed: 08-Oct(2014)].

\section{Authors}

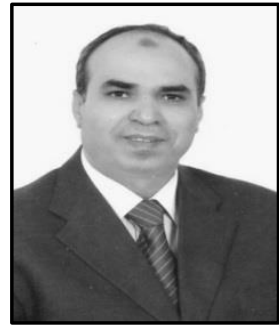

Prof. Mohammed Abo-Zahhad, he received his B.S.E.E. and M.S.E.E degrees in electrical engineering in 1979 and 1983 respectively, both from Assiut University (AU), Egypt. In 1988, he received $\mathrm{Ph}$. D. degree from the University of Kent at Canterbury, UK and AU (channel system). His research interests include switched-capacitor, optical and digital filters, biomedical and genomic signal processing, speech processing, data compression, wavelet-transforms, genetic algorithms, immune algorithms, wireless sensor networks and electronic systems. He has published more than 110 papers in national and international journals and conferences in the above fields. Professor AboZahhad is currently a Professor of Electronics and Communication Engineering, since Jan. 1999. Also, he is the director of AU Management Information System (MIS) center and a vice-dean for graduated studies, Faculty of Engineering, AU, since August 2006. From August 2006 till July 2013 he was the vice dean for graduate studies, Faculty of Engineering, AU. Since November 2013 he has been elected as the chair of Electrical and electronics engineering Department, $\mathrm{AU}$. He is a member of the European Society of Circuit Theory and Applications, since 1998 and a senior IEEE member, since 2000.

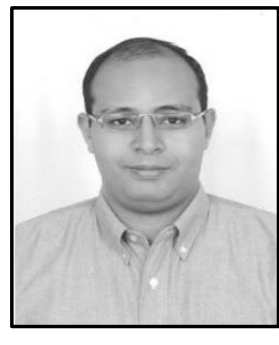

Dr. Osama Amin, he received his B.Sc. degree in electrical and electronics engineering from South Valley University, Aswan, Egypt, in 2000, the M.Sc. degree in electrical engineering from Assiut University, Assiut, Egypt, in 2004, and the Ph.D. degree in electrical and computer engineering from University of Waterloo, Waterloo, ON, Canada $\mathrm{He}$ is currently a Postdoctoral Fellow with the Department of Electrical and Computer Engineering, University of British Columbia, Vancouver, BC, Canada. His research interests 
include cooperative communications, power line communication, adaptive systems, orthogonal frequency-division multiplexing, green communication, and channel estimation.

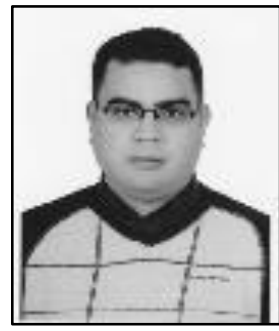

Dr. Mohammed Farrag, he received his B.Sc. degree in electrical and electronics engineering from Assiut University, Assiut, Egypt, in 2001, the M.Sc. degree in electrical engineering from Assiut University, Assiut, Egypt, in 2008, and the Ph.D. degree in electrical and electronics from Egypt-Japan University of Science and Technology, in 2013. His research interests include cooperative communications, Dynamic spectrum access, Cognitive Radio, orthogonal frequency-division multiplexing, green communication, and Compressive sensing applications.

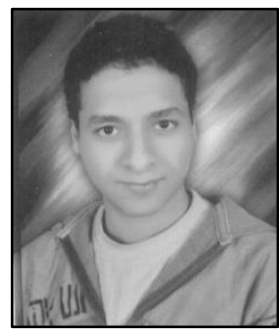

Eng. Abdelhay Ali, he received his B.Sc. (honors) degree in Electrical and Electronics Engineering Department, Faculty of Engineering, Assiut University, Assiut, Egypt, in 2012. He is currently a demonstrator of electrical engineering, Assiut University, Egypt and pursuing the M.S. degree in modeling of wireless sensor networks with maximum lifetime and minimum energy consumption. His main research interest is in wireless sensor networks with specific focus on maximize lifetime of wireless sensor networks. 
International Journal of Energy, Information and Communications Vol.5, Issue 6 (2014) 